\section{Determination of reference intervals for total calcium and magnesium specific for children and adolescents in Sibiu area}

\section{DOI: $10.1515 / \mathrm{rrlm}-2016-0030$}

Total calcium and magnesium are two minerals whose presence is essential for the body, their deficiency causing severe damage to the metabolic functions.

Therefore, it is very important to recognize the reference intervals adapted to the population of Sibiu area in order to make quick and accurate decisions in terms of health or illness, as well as regarding treatment and taking supplements of calcium and magnesium because, as they are not synthesized in body in order to ensure the daily requirements of magnesium and calcium, the conditions for a proper diet rich in minerals should be established, and supplemented with magnesium and calcium $(1,2)$.

Conventionally, reference intervals are determined by using data sets consisting of the results obtained in an apparently healthy population using the $95 \%$ confidence interval to define the normal limits $(3,4)$.

The term "reference interval" was introduced in 1969 by Grasbeck and Saris with a view to replace the old definition of "normal values" (4).

In paediatrics, recruitment of reference individuals is particularly difficult because of changes taking place due to the growth and development of the child. Reference individuals are selected using "well defined criteria" which vary from one study to another (5).

Our team aims at determining our own reference intervals for children and adolescents in
Sibiu area given the equipment we are working with, working reagents, and protocols. We decided to determine reference intervals using the Hoffmann (6) method, because our team has previously used this method for getting these ranges for haemoglobin (7). To accurately interpret the results of the analyses performed, these ranges will be obtained according to age groups.

The reference ranges obtained by us will be compared with those in Lothar Thomas' Manual, Clinical Laboratory Diagnostics, 1998 (8) and Roche Diagnostics Manual, 2004 (9).

The study involved patients of Sibiu Paediatric Hospital. The study was made possible by the use of data (results) selected from the electronic database of the laboratory. Using the results of the database was approved by the Ethical Committee of the hospital. The study included results from blood samples collected during a year from children and adolescents, hospitalized or outpatients.

There is no conflict of interest regarding this study.

Determination of total calcium and magnesium was performed on Konelab Prime 30i. analyzer. It is calibrated using the calibrator (Duna$\mathrm{Cal}$ ) and tested with control serum using normal sera (Duna Cont N) and pathological sera (Duna Cont $\mathrm{P}$ ) before actual testing. Samples are carried out only if the results of the checks fall within the ranges given by the manufacturer.

All samples of blood to determine total serum calcium and magnesium were collected by venepuncture into vacutainers without anticoagulant. The blood collected was kept at room temperature then centrifuged at $3000 \mathrm{rpm}$ for 10 minutes.

The analysis of total serum calcium was performed from serum using Arsenazo III rea- 
gent, which together with calcium ions forms a strongly coloured complex which is measured by spectrophotometry at $660 \mathrm{~nm}$ wavelength. Determination of magnesium was performed in serum using a colour reagent, xylidyl blue, which reacts with magnesium ions in an alkaline environment to form a water-soluble purple-red chelate, measured at a wavelength of $510 \mathrm{~nm}$.

We analysed data from about 5100 patients aged 1 month to 18 years old, divided into several age categories according to the classification made by our Clinic.

Hoffmann indirect method uses the results from the database, subjects having minimal pathology, and taking into account $5 \%$ up to $95 \%$ of the values obtained, the values being randomly selected.

Hoffmann method requires removing these aberrant values by using the Chauvenet criterion; it refers to the elimination of values whose probability of occurrence is less than $1 /(2 \mathrm{~N})$, where $\mathrm{N}$ is the number of values taken into account and it should be less than 4 in this study (6).

After eliminating these values considered inappropriate, data were reviewed and cumulative frequency was established.

Cumulative frequency is:

$$
\mathrm{CF}_{\mathrm{Xi}}=\sum_{k=2}^{i} F_{X K} \quad \text { ordered by } \mathrm{X}_{\mathrm{i}} \text {. }
$$

$\mathrm{F}_{\mathrm{Xi}}$ is the frequency of a result of analysis and is equal to the ratio between the number of occurrences of a result in the data set and the total number of data, all multiplied by $100 \%$.

Data was represented on the chart, and by visual assessment, the portion of the line linearity was established. The trajectory of this line is fixed on the basis of a mathematical model, called "the method of least squares", which minimises the distances between the real points and the regression line (6).
The best equation of the regression line is $Y_{i}=\alpha X_{i}+\beta$, where: $\alpha$ is the slope and $\beta$ is the intercept of the line.

By solving the regression equation, the maximum $\left(\mathrm{RI}_{\max }\right)$ and minimum $\left(\mathrm{RI}_{\min }\right)$ values were determined, given that the values must be within the range $2.5 \%$ and 97 .

$\mathrm{RI}_{\max }=\alpha \cdot 97.5+\beta$ and $\mathrm{RI}_{\min }=\alpha \cdot 2.5+\beta$ (6)

Reference intervals obtained were then compared with those in the Lothar Thomas Manual - Clinical Laboratory Diagnostics 1998 (8) and the Roche Diagnostics Guide 2004 (9).

Using the data sets taken from the electronic archive of the laboratory, we established the cumulative frequency for total serum calcium and magnesium in the patients selected per age groups.

We presented the chart indicating the cumulative frequency for total calcium and magnesium. The charts revealed that the regression functions and the reference ranges were calculated using the indirect Hoffmann method $\left(\mathrm{RI}_{\min }\right.$ and $\left.\mathrm{RI}_{\max }\right)$.

It was not possible to calculate reference intervals for children under 1 month old because sufficient data were not available, minimum 120 data being needed according to the Hoffmann method.

For total calcium, in the age group of 1 to 3-year olds, we obtained almost identical values with those stated in the Lothar Thomas Manual - Clinical Laboratory Diagnostics (8), as well as in the Reference Intervals Manual - Roche Diagnostics Guide (9). For the same age group, reference intervals obtained for magnesium were between 0.66 and $1.12 \mathrm{mmol} / \mathrm{L}$. For the age group of 1-3-year olds, the lower limit of the reference intervals is similar to that shown in the two guides, the upper limit of the reference ranges obtained is slightly higher compared with the studied literature. 
Table 1. Comparison between reference ranges calculated for magnesium and the reference ranges reported in literature. Lothar Thomas Manual Clinical Laboratory Diagnostics (8) and Roche Diagnostics (9).

\begin{tabular}{|c|c|c|c|c|c|c|}
\hline Analyte & Age groups & $\begin{array}{l}\text { No. of } \\
\text { patients }\end{array}$ & $\begin{array}{l}\text { Regression } \\
\text { function }\end{array}$ & $\begin{array}{l}\text { Calculated } \\
\text { reference } \\
\text { interval } \\
\end{array}$ & $\begin{array}{l}\text { Reference } \\
\text { interval (8) }\end{array}$ & $\begin{array}{l}\text { Reference } \\
\text { interval (9) }\end{array}$ \\
\hline \multirow[t]{3}{*}{$\begin{array}{l}\text { Calcium } \\
(\mathrm{mmol} / \mathrm{l})\end{array}$} & $\begin{array}{l}1 \text { month - } \\
3 \text { years old }\end{array}$ & 1478 & $0.0048 x+2.1561$ & $2.17-2.63$ & $2.17-2.44$ & $2.1-2.6$ \\
\hline & 4-6 years old & 1423 & $0.0040 \mathrm{x}+2.1772$ & $2.19-2.57$ & $2.19-2.51$ & $2.3-2.75$ \\
\hline & $7-18$ years old & 2189 & $0.0045 x+2.1353$ & $2.15-2.57$ & $2.19-2.66$ & $2.3-2.75$ \\
\hline \multirow[t]{4}{*}{$\begin{array}{l}\text { Magnesium } \\
(\mathrm{mmol} / \mathrm{l})\end{array}$} & $<1$ month old & 14 & - & - & $\begin{array}{l}\text { New-born: } \\
0.48-1.05\end{array}$ & $\begin{array}{l}\text { Preemies } \\
0.57-0.78\end{array}$ \\
\hline & $\begin{array}{l}1 \text { month - } \\
3 \text { years old }\end{array}$ & 2071 & $0.0048 x+0.6510$ & $0.66-1.12$ & - & \multirow{3}{*}{$\begin{array}{l}\text { - Children } \\
\text { and adults } \\
-0.70-1.05\end{array}$} \\
\hline & 4-6 years old & 827 & $0.0035 x+0.6878$ & $0.69-1.03$ & $\begin{array}{l}\text { School-aged chil- } \\
\text { dren: } 0.60-0.95\end{array}$ & \\
\hline & $7-18$ years old & 2193 & $0.0036 x+0.6681$ & $0.67-1.02$ & $\begin{array}{l}\text { School-aged chil- } \\
\text { dren: } 0.60-0.95\end{array}$ & \\
\hline
\end{tabular}

Regarding the age group of 4-6-year-old, our study showed a reference interval for total calcium, with the lower and upper limits being lower when compared with the survey conducted by Roche Diagnostics Guide (9), but identical to the reference ranges presented in the Lothar Thomas Manual - Clinical Laboratory Diagnostics (8). The reference intervals obtained for magnesium in the age group of 4-6-year-olds were nearly identical to the reference ranges mentioned in Roche Diagnostics Guide (9). It is more relevant to make interpretations according to the reference ranges presented in this guide, the range being closer to our specific population. Reference intervals obtained in the current study show the lower and upper limits slightly higher compared with the Lothar Thomas Manual - Clinical Laboratory Diagnostics (8).

For children aged 7 - 18 years old, our study showed differences from total calcium as compared to the limits shown by Roche Diagnostics Guide (9), because the age group was divided differently. Reference intervals shown in our study are closer to those shown in the Lothar Thomas Manual (8). For the same age group, the reference ranges obtained for magnesium are almost identical to the reference intervals stated by Roche Diagnostics Guide (9), but slightly higher compared with the reference ranges reported by the Lothar Thomas Manual - Clinical Laboratory Diagnostics (8).

Thus, we can state that the values obtained in the current study are similar to those reported in the literature and that the values we use are valid for the population concerned.

It should be mentioned that we did not calculate whether the difference between the values obtained by us and those found in the literature is statistically relevant because studies were not conducted in the same manner, using the same laboratory equipment.

The obvious advantage of this approach is that it eliminates the need to recruit healthy people taking advantage of the data from the hos- 
pital which have already been collected and are available.

Taking into account the difficulty of selecting "healthy" patients within hospital and outpatient structures, especially in terms of ethnicity, the values obtained are similar to those published in the studied literature.

Reference intervals obtained in this study are specific to the population of Sibiu area and cannot be extrapolated to other medical facilities without being validated, as health systems (population, apparatus, method, reagents) can greatly vary between different centres or countries. The validation process consists of the collection and testing of 20 samples from healthy volunteers.

Establishing reference intervals is a powerful instrument in laboratory medicine, providing valuable information for the correct interpretation of laboratory results and helping clinicians to make correct decisions.

\section{Elisabeta Antonescu ${ }^{1}$, Juliánna Szakács ${ }^{2, *}$, Maria Totan 1,3}

1. "Lucian Blaga" University of Sibiu, Faculty of Medicine, Sibiu, Romania;

2. Department of Biophysics, University of Medicine and Pharmacy Tîrgu Mureș, Tîrgu Mureș, Romania;

3. Clinical Hospital of Pediatrics Sibiu, Sibiu, Romania.

* Corresponding author: Juliánna Szakács, e-mail: szjulianna@gmail.com

Received: 05 ${ }^{\text {th }}$ November 2015; Accepted: $26^{\text {th }}$ August 2016; Published: 30 ${ }^{\text {th }}$ August 2016.

\section{References}

1. Bilezikian JP, Marcus R, Levine MA, Marcocci C, Silverberg SJ, Potts Jr JT. The parathyroids: basic and clinical concepts. Academic Press, Chapter 48, Gordon LK. Magnesium Depletion and Parathyroid Function. 2014;697-706.

2. Castiglioni S, Cazzaniga A, Albisetti W, Maier JA. Magnesium and osteoporosis: current state of knowledge and future research directions. Nutrients. 2013;5(8):3022-3. DOI: 10.3390/nu5083022.

3. Roizen JD, Shah V, Levine MA, Carlow DC. Determination of Reference Intervals for Serum Total Calcium in the Vitamin D-Replete Pediatric Population. J Clin Endocrinol Metab. 2013;98(12):1946-50. DOI: 10.1210/jc.2013-3105.

4. Liu J, Yuan E, Zhang Z, Jia L, Yin Z, Meng X, et al. Age- and sex-specific reference intervals for blood copper, zinc, calcium, magnesium, iron, lead, and cadmium in infants and children. Clin Biochem. 2012;45(6):4169. DOI: 10.1016/j.clinbiochem.2012.01.014.

5. Kulasingam V, Jung BP, Blasutig IM, Baradaran S, Chan MK, Aytekin M, et al. Pediatric reference intervals for 28 chemistries and immunoassays on the Roche cobas ${ }^{\circledR} 6000$ analyzer-A CALIPER pilot study. Clin Biochem. 2010;43(13):1045-50. DOI: 10.1016/j.clinbiochem.2010.05.008.

6. Katayev A, Balciza C, Seccombe DW. Establishing reference intervals for clinical laboratory test results. Am J Clin Pathol. 2010;133(2):180-6. DOI: 10.1309/ AJCPN5BMTSF1CDYP.

7. Totan M, Gligor FG, Bojita M, Grigore C, Grigore C. Determining hemoglobin reference values in children and teenagers from Sibiu area. Rev Romana Med Lab. 2013;21(1):39-45. DOI: 10.2478/rrlm-2013-0016.

8. Lothar T. Hemoglobins, Clinical Laboratory Diagnostics, Use and Assesment of Clinical Laboratory Results - Frankfurt/Main : THBooks Verlagsgesellschaft GmbH. 1998;475-6.

9. Heil W, Koberstein R, Zawta B. Reference ranges for adults and children. Pre-Analytical Considerations. Roche Diagnostics Guide GmbH. Mannheim. 2004. 